WellBeing International

WBI Studies Repository

1984

\title{
Human/Animal Communication: Cetacean Roles in Human Therapeutic Situations
}

M. Patricia Hindley

Simon Fraser University

Follow this and additional works at: https://www.wellbeingintlstudiesrepository.org/acwp_aat

Part of the Animal-Assisted Therapy Commons, Animal Studies Commons, and the Other Anthropology Commons

\section{Recommended Citation}

Hindley, M.P. (1984). Human/animal communication: Cetacean roles in human therapeutic situations. In M.W. Fox \& L.D. Mickley (Eds.), Advances in animal welfare science 1984/85 (pp. 75-85). Washington, DC: The Humane Society of the United States.

This material is brought to you for free and open access by WellBeing International. It has been accepted for inclusion by an authorized administrator of the WBI Studies Repository. For more information, please contact wbisr-info@wellbeingintl.org.

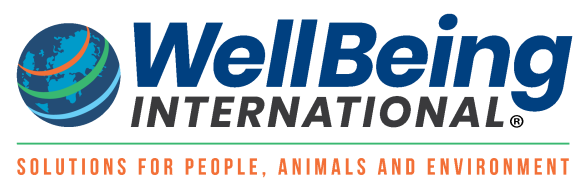




\title{
HUMAN/ANIMAL COMMUNICATION: CETACEAN ROLES IN HUMAN THERAPEUTIC SITUATIONS
}

\author{
M. Patricia Hindley*
}

\author{
Department of Communication \\ Simon Fraser University \\ Burnaby, B.C. \\ Canada, V5A $1 S 6$
}

\section{INTRODUCTION}

A review of the literature on the relationship between animal and human indicates that whales and dolphins may have a mutually beneficial role to play in human therapeutic situations. Florida researchers have discovered that interaction with dolphins has favourably altered the behaviour of neurologically impaired people, and of autistic children who are usually withdrawn and uncommunicative.

Explorations with both wild and captive cetaceans may find suggestive direction from extensive research currently being done with pets and domestic animals. Growing scientific evidence suggests that animals can benefit not only the physically and mentally ill, the lonely and the incarcerated, but also the minds and bodies of healthy people as well. Research done at, for example, the University of Pennsylvania's Center for Interaction of Animals and Society, the University of Minnesota's Center for Study of Human-Animal Relationships

\footnotetext{
*Paper presented at the IWC Non-Consumptive Utilization of Cetacean Resources Conference, Boston, June 1983.
} 
and Environments, the University of Cambridge, and by members of the Society for Companion Animal Studies in Paris, indicates marked therapeutic benefits from the involvement of animals in a variety of human situations.

\section{DOMESTIC ANIMALS}

In healthy people it has been found that animals act as "social lubricants," that is, they facilitate social interactions between owners and other people which often result in friendships (Mugford and M'Comisky 1974; Messent 1982). They provide companionship, affection and tactile contact for people whether they live alone or not. It seems to be a reciprocal exchange of affection and contact between human and animal. People report greater feelings of self-esteem, of having permission to be overtly affectionate, and to openly touch and fondle (the latter reported especially by men). They also felt animals allowed them to forget themselves and their problems and to engage in playfulness.

Interestingly enough there is little evidence to suggest that more than a small minority of people use animals as a substitute for human companionship. Rather an animal is seen as an "addition to," albeit an important one (Adell-Bath et al., 1979). In one study done by Katcher (1981), about $80 \%$ of the participants regarded their animals "as a person" and talked to them regularly. The value of a companion who does not "talk back" or criticize, seems to be of particular importance in the early lives of children.

Boris Levinson, a pioneer in the field of animal/children bond research, has demonstrated the value of pet animals in child development (Levinson 1969, 1972, 1978). Pets, he claims, can be major sources of emotional support, acting as friend and confidante, providing a constant source of love and tactile affection. They also enable the child to learn how to take responsibility and care for another, they also can provide disciplinary models. During times of bereavement, loss or similar stress, children with animal companions often fare better - the animal seems to provide continuity.

Levinson has also written about the use of animals in psychotherapy with children. He identifies a pattern in which the child first talks only to the dog, ignoring the therapist, then includes the therapist in the conversations with the dog, thus eventually able to deal directly with the therapist. For disturbed and psychotic children an animal may be the only animate object with which they can make contact in their struggle to establish positive human relationships again (Searles 1960). The unquestioning loyalty, total acceptance and uninhibited af- 
fection of the animal seem to be key factors in successful therapy with children whose communication with adults has either ceased or become disturbed. Successful work has been done with physically handicapped children in West Germany. It was found, for instance, that pet horses were very popular. Seated high in the saddle, a wheelchairbound child could for once in her life look down on everyone and "maintain a sense of dignity."

Animals have also been used successfully with adults in mental hospitals, especially with those patients for whom all "other available therapeutic methods failed to bring about significant improvement" (Corson, Corson, and Alexander 1980). The patients were withdrawn, uncommunicative, self-centered, almost mute and psychologically bedridden. The introduction of an animal saw a gradual but significant shift towards self-esteem, responsibility and independence with increased mobility and a reaching out to others.

Similar success has been achieved by the Corsons, using pets on geriatric wards. One elderly man who had not spoken for 26 years, spontaneously said "You brought that dog," upon receiving a dog as a long-shot part of therapy. He later made friends and became quite an accomplished painter of animals. The introduction of birds to geriatric wards and to elderly people living alone has had quite remarkable positive effects from raising self-esteem, creating group cohesion, making friends, to maintaining health (Mugford and M'Comisky 1974). The researchers commented on the "surprisingly intimate and presumably rewarding attachment to these unsolicited pet birds." The typical view of a geriatric ward population as helpless, hopeless, and waiting to die becomes quite the opposite as normal healthy responses to life dormant in the company of our own kind, are triggered by other species.

This has also been true at Lima State Hospital in Ohio, a maximum security institution housing about 400 patients, including psychopaths and sex offenders. To date nearly 100 patients are involved in pet facilitated therapy. The $85 \%$ attempted suicide rate in the hospital in general dropped to zero seven years ago on those wards involved in pet therapy, and has remained there. The hospital has 20 aquaria and 160 animals including parrots, gerbils, rabbits, hamsters, guinea pigs and deer. While controlled studies need to be done, positive indications are the giving of humane and loving care to animals and improved social relationships. Similar results have been obtained with the use of farm animals and pets in psychotherapy with delinquent children in residential schools (Levinson 1972). Again the emotional and tactile contact with loving, non-critical animals may help diffuse feelings of hostility, alienation and rejection common in criminal offenders and anti-social behaviour. 


\section{EXPERIMENTAL ANIMALS}

Evidence indicates that benefits accruing to us from the animal/human bond are not only psychosocial but also physiological. It has been found that in healthy people blood pressure and pulse rate drops when, for example, petting or talking to their animals, or when viewing a tank of tropical fish. In contrast blood pressure and heart rate increase when talking to other people, reading aloud, but again can be reduced if an animal is present in the room (Katcher and Friedmann 1980). The same researchers also found that the ownership of a pet was the factor most highly correlated with one year survival following a heart attack, apart from the physiological severity of the disease. Exercise and need for companionship were rejected as the main explanations since the group of patients included both married and single people, and also owners of small house-bound pets. Rather it may be that "dumb as opposed to speaking companions" offer a fuller explanation since "the speechless kind of companionship shared with pets may provide a source of relaxation that human companions who demand talk as the price of companionship may not provide" (Friedmann et al., 1980).

For experimental work done with animals in the laboratory during which animals are often subjected to abhorrent levels of pain and deprivation, it has been found that similar benefits accrue to the ani$\mathrm{mal}$ if they are in the presence of a sympathetic human. This is even more true if they are in physical contact. Such benefits are reduction of anxiety, lowering of blood pressure and heart rate, and increase in coronary blood flow.

Twenty years ago Gantt conducted research on the "effect of person" or effect of human contact on animals. He found significant variations in heart rate when an electric shock was administered to a dog's foot when the animal was alone and when it was being petted by a person. While being petted the heart rate increase was reduced by half. Similarly when the dog received a warning bell signalling the approach of shock, heart rate increased dramatically. If a person petted the dog during both bell and shock then the increase in heart rate was either eliminated or even reduced (Gantt et al., 1966). Clearly, human contact had made an enormous difference lending some credence to Darwin's belief that petting and contact in animals was an expression of love. Such experimental findings suggest that the animal/human bond is as important to the animal as it is to the human.

Other laboratory findings indicate emotional reactions in animals which closely parallel human behaviour, making reciprocity in the relationship even more believable. While much behaviour is species specific and it is dangerous to generalize to human behaviour, nevertheless, 
the parallels throw valuable light on the nature of the human/animal bond. According to some researchers emotional disorders such as anorexia, depression, neurotic behaviour, perversions, and criminal disorders have been observed in farm animals and pets, all intelligible in terms of recent stress or early history (Saul 1962).

The classic work of Harlow and his colleagues on total deprivation of tactile companionship in infant monkeys indicates similar emotional reactions to stress. One of the most interesting findings was the constant selection of the cloth surrogate mother during times of anxiety and insecurity even though the wire surrogate mother provided milk. It seemed that contact comfort was of overwhelming importance. Experiments in which infant monkeys could see but not touch their mothers, produced similar but less intense disturbances and distress. A further unexpected finding was that even though the cloth mother was inanimate, the infant felt such emotional security through warmth and body contact alone, that it was able to explore new objects in its surroundings. It was once thought by Harlow that infant monkeys reared from birth to six months in total isolation would never exhibit normal behaviour. However more recently he reports that if the right kind of body contact is provided, the behaviour is reversible (Suomi, Harlow, and McKinney 1972).

For instance, artificially inseminated mothers reared in isolation sometimes succumb to the pestering to cling by their determined offspring, such that they rear their second born normally. Secondly, heated cloth surrogate mothers given to six month old isolates produces positive social behaviour after a few weeks of intense clinging. Similar results are achieved when normal but younger pre-aggressive infants are placed in cages with six month old isolates. While the isolate withdraws, the normal infant's tendency is to cling. Again body contact is influential with the isolate. Another interesting observation of animal need for contact was reported by Coelho (1980). He observed a baboon in a primate colony adopt a feral kitten. As in the case of the human/pet bond the baboon was seen to hold the kitten close, to pet it and to use it as a social facilitator in interactions with other baboons.

Findings therefore show that two main elements in the animal/ human bond are trust and touch. In the case of humans as has been said, there is ample evidence that a warm trusting and trustworthy non-human creature is often a key to health. In the case of both animal and human, it seems clear from the data that the addition of touch has not only positive and emotional effect on both, but is essential for normal development. Montagu (1978) reminds us of the general embryological law which says that the earlier a sensory system becomes functional, the more fundamental it is likely to be. Since touch is the 
earliest sensory system to develop, he argues that it must have profound psycho-biological significance for normal behavioural and physical development. In addition to the evidence of abnormal development in animals deprived of touch, there is evidence of similar abnormalities in humans. Children raised by parents or others who for reasons of insensitivity, emotional instability, cruelty or belief, withhold contact (touching, stroking, fondling) and affection from them, exhibit abnormal psychological development. This may continue into adult life and be perpetuated on their own children. It is of interest that battering and abusing parents, treated similarly themselves as children, rarely report having a pet.

Montagu also refers to positive results of tactile contact in animals. For instance he comments that hand-milked cows give more and richer milk than machine-milked cows, that using touch to gentle young rats makes them better able to tolerate stressful situations as adults, and that dolphins like to be gently stroked.

\section{CETACEA}

In captivity, social interaction, including tactile contact between trainer and dolphin is standard practice and seen to be an important factor in bonding the relationship and developing good rapport. We know from trainers' and researchers' reports that such bonds can be unusually strong-more so than with other animals - and that separation can result in very stressful experiences for both trainer and dolphin (Lilly 1967).

There seems to be ample evidence now, and in any case it seems reasonable to extrapolate from the data on other highly evolved social animals (wolves, elephants, primates), that social interaction and tactile contact are of significant importance to many species of cetacea. We know, for example, that their skin is a highly refined sensory organ of touch and that in groups of whales and dolphins physical contact is necessary and frequent. As in the case of other animals, cetacea/human bonding seems to involve a mutual need for touching and stroking, and also seems to involve (at least, as observed in captivity) mutually strong emotional ties. It is well known that when captured or placed in stressful situations, dolphins respond well to human touch. Robson has commented that when touched and stroked and spoken to soothingly, stranded whales become calm and less stressed.

Animal/human bond research has in fact included work with captive dolphins. Henry Truby, one of John Lilly's colleagues, observed play interaction between neurologically impaired people and dolphins and concluded that they were mutually beneficial. More recently in 
1978, Truby and Smith, a Florida researcher, started to explore whether captive dolphins could have a positive effect on the behaviour of autistic children. Infantile autism, characterized by delayed and deviant language development, severely impaired capacities to relate to people and objects, extreme withdrawal and failure to respond to sensory stimuli, is sometimes called a communication disease. Any modicum of success with these children can be regarded as a breakthrough.

In the Florida study with eight autistic children, all eight showed, amongst several behaviour improvements, unusually long attention spans. One boy, Michael, an 18 year old, fed fish to dolphins, poured water over them and made clicking noises to gain their attention. Not only was such interactive play behavior, that is reaching out beyond himself, highly unusual, but beyond speaking two words, he had never before made efforts at verbal communication. Smith reports not only temporary but sustained changes in his behaviour, namely, excitement on seeing dolphins, grabbing other people to indicate the dolphins, recognition of and clicking at dolphins on television and in books, and the use of the word "yep" five times in one week in response to questions about dolphin visits (Smith 1982).

There is as yet no available data on the dolphins' reaction to these children, but recognizing the intractable nature of this emotional disorder and the unusually positive results, interesting speculations might be made about the value of cetacea in this kind of work.

The literature indicates that cetaceans historically have demonstrated a benign interest towards us, and that, in the face of some of our worst atrocities. It further demonstrates a strong emotional pull towards cetaceans on the part of humans since the earliest times. Cetaceans have shown interest in us in a variety of ways. There are many examples of the lone dolphin establishing strong relationships with people in local waters, sometimes selecting particular individuals, often children, e.g., Opo and Horace in New Zealand, Donald in Britain, Jean Louis in France, and Sandy in the Bahamas. Wade Doak has collected hundreds of anecdotes from divers, sailors, long distance swimmers, surfers, etc., commenting on their dolphin encounters -playing, being protected from sharks, guided to safe waters, being accompanied, seeking contact, etc. (Doak 1981). Relatively recently scientists have become aware of a unique situation on the remote coast of Western Australia at Monkey Mia, where for the last 16 years a group of dolphins have been visiting the beach to interact with people. Fish are fed to the dolphins but there is also a great deal of tactile contact and vocal exchanges. While most scientists are convinced that the food reward is quite secondary to the importance of social interaction, no controlled studies have yet been carried out. The amount of reported evidence of even whales seeking contact with humans is in- 
creasing, e.g., humpbacks in Hawaii, greys in Mexico, sperm in New Zealand, and right whales in Patagonia.

There seems to be little doubt that tactile contact between humans and animals is not only mutually beneficial but also mutually pleasurable. Messent (1981) commented that in our society the need for tactile contact and the opportunity to satisfy it may have values we do not yet understand. It may well be that it is of paramount importance to us because it represents an outward expression of the emotion of love. Darwin (1955) in his book The Expression of Emotions in Man and Animals shocked the scientific community in 1872 with his claim that human expression of emotion, although more differentiated was similar if not identical to that in animals. Emotions were expressed in all creatures in a manner designed to effectively communicate to others what was being felt inside. He stated that the emotion of love was an exception to all the general rules in that while it was the most powerful of all emotions, it was the only one with no special means of expression:

Although the emotion of love, for instance that of a mother for her infant, is one of the strongest of which the mind is capable, it can hardly be said to have any proper or peculiar means of expression....A strong desire to touch the beloved person is commonly felt...love is expressed by this means more plainly than by any other.... With the lower animals we see the same principle of pleasure derived from contact in association with love.

\section{DISCUSSION}

While most of us would agree with Darwin that "the emotion of love...is one of the strongest of which the mind is capable," we also have to wonder why scientists in the twentieth century accepted Darwin's theories but almost totally neglected the study of the emotion he deemed most important.

The sensitivity of touch and its relationship to the emotion of love certainly raises some questions about both the importance of animals in our lives and the nature of animal emotion and consciousness. It also raises important questions about cetacea and our relationship with them. The history of close encounter with cetacea may not be accidental if Alistair Hardy is correct that we were once aquatic apes living in the shallows in close harmony and possibly close tactile contact with coastal cetacea, rather than in the prey/predator relationship as with most other animals (Morgan 1982).

Given the intelligence of dolphins, the innumerable instances of sensitive behaviour towards people and their affinity for children, the 
therapeutic benefit could be quite extraordinary. Particularly so since at the present time we do not know very much about the minds of other species and in what ways they communicate non-verbally, least of all about the big-brained acoustically oriented cetacea.

At least there now seems to be some shift away from our traditional arrogant and anthropocentric way of viewing animal behaviour. Scientists are considering heretofore heretical ideas about the intelligence, culture, language and consciousness of animals (Norris, Pribram, Terrace, J.J. Bonner, etc.). Speculation has it that some species of whales and dolphins might be able to transmit and interpret visual thought patterns. If there is any truth in this then therapeutic interaction with severely disturbed people, the blind, the deaf and others whose communication patterns are hindered, might be of primary importance.

While this author is not in favour of captivity, it nevertheless remains true that permits for capture are still being issued and that a number of cetaceans are now in captivity and will likely remain so for several more years. These social animals whose need for love and affection, social interaction and tactile contact may be no less than ours, and who have demonstrated over the centuries a desire to interact with humans, may benefit equally from therapeutic interactions. Such involvements may well outstrip any psychological benefits currently accruing from their involvement in cognitive research and entertainment.

While in some ways it seems less practical to involve wild cetaceans, it may become less so as: (a) the whale sighting tourist industry increases; and (b) reports of locations of friendly whales and dolphins increases. Again, and this is equally speculative, it may be that those amongst us, who for reasons of physical handicap or emotional trauma, chose or are forced to use uncommon modes of communication, could find meaningful affective communication with cetacea, as yet indecipherable to the rest of us in our logical linear world.

\section{CONCLUSION}

This evidence of mutual benefit from interaction is hardly surprising if we pause to think about our biological and evolutionary heritage, of the intricate interdependency between human and animal down the ages. It appears likely that the human/companion animal bond is of great antiquity beginning perhaps with man's capacity to reach out to the young of wild animals, culminating about 12,000 years ago in domestication of canids. It is clear that animals are still important to modern man-not just for material resources, when we consider that there are approximately 35 million dogs and 25 million cats in Ameri- 
can households alone. In terms of our psychological development, the animal is a universal dream symbol, playing a powerful role, not only in our dreams, fantasies, folktales, art and religion, but in our neuroses and psychoses. Our children are said to first dream of animals (Levinson 1972).

However, an explanation of the evolution of our attitudes towards nature, in general, and animals in particular, reveals a relatively recent but ever increasing shift from cooperative interdependence to competitive independence, with an almost complete and arrogant disregard for our biopsychological kinship and needs. Much has been written on the demise of species and environments and possibly the planet itself under the domination of the human animal (e.g., Leiss 1974). While we have "successfully" domesticated nature, bringing it close to the brink of total disaster, it could clearly be argued that we have severely lost rather than gained in personal contentment, psychological stability and social cohesion-witness, for example, the human agony in our hospitals, mental institutions and prisons, and the perplexities and confusions in ourselves and our everyday lives.

Human-animal bond research with its rather ironic findings that not only do healthy people benefit from such a bond but that in some cases animal therapy is the only therapy to give any positive results, may help to provoke a much needed return to a respect for and a cooperation with other species, both wild and domestic.

Much has been written about species interdependency in terms of basic survival needs. Relatively little has been written about the possiblility of species interdependency at an emotional level. Involving cetaceans in therapeutic situations may usefully extend the range of human/animal bond research in ways which could be important to the mental and physical well being of many species, including humans. Considering the impressive results from therapeutic work with pets and domestic animals, how much more dramatic might the results of such work be with animals whose brain capacity is much close to our own?

We may even come to acknowledge a primary human need to live cooperatively with other species. Finally, in the ironic fact of their sometimes unique capacity to guide us back to sanity, we may also acknowledge their qualitatively equal differences and therefore their equal rights to survival. 


\section{REFERENCES}

Adell-Bath, M., Krook, A., Sandquist, G., and Skantze, K. 1979. Do we need dogs? A study of dogs' social significance to man. University of Gothenburg.

Coelho, A.M. Jr. 1980. Guardian behavior by baboons towards felines. Laboratory Primate Newsletter 19:1-10.

Corson, S., O'Leary Corson, E., and Alexander, J.A. eds. 1980. Ethology and nonverbal communication in mental health: An interdisciplinary biopsychosocial exploration. London: Pergamon Press.

Darwin, C. 1955. The expressions of the emotions in man and animals. New York: Philosophical Library.

Doak, W. 1981. Dolphin dolphin. Auckland, N.Z.: Hodder \& Stoughton.

Friedmann, E., Katcher, A.H., Lynch, J.J., and Thomas, S.A. 1980. Animal companions and one-year survival of patients after discharge from a coronary care unit. Public Health Reports 95(4, July-August):307-12.

Gantt, W.H., Newton, J.E.O., Royer, F.L. and Stephens, J.H., 1966. Effect of person. Conditional Reflex 1:18-34.

Katcher, A.H. 1981. Interaction between people and their pets-form and function. In Fogle, B. ed. Interrelations between people and pets. Springfield, Illinois: Chas. C. Thomas.

Katcher, A.H. and Friedmann, E. 1980. Potential health value of pet ownership. The Compendium on Continuing Education 11(2,February):117-21.

Leiss, W. 1972. The domination of nature. Boston: Beacon Press.

Levinson, B. 1971. Household pets in training schools serving delinquent children. Psychological Reports 28:475-81.

Levinson, B. 1972. Pets and human development. Springfield, Illinois: Chas. C. Thomas.

Levinson, B. 1978. Pets and personality development. Psychological Reports 42:103138.

Levinson, B. 1969. Pet oriented child psychotherapy. Springfield, Illinois: Chas. C. Thomas.

Lilly, J.C. 1967. Mind of the dolphin. New York: Avon Books.

Messent, P.R. 1982. Increase in people-people contacts through dogs as social catalysts. For presentation at 20th International Congress of Applied Psychology, Edinburgh, 28 July 1982, pp. 25-31.

Montagu, A. 1978. Touching. New York: Harper and Row.

Morgan, E. 1982. The aquatic ape. London, England: Souvenir Press Ltd.

Mugford, R.A. and M'Comisky, J. 1974. Some recent work on the psychotherapeutic value of cage birds with old people. In Anderson, R.S. ed. Pet animals and society. London: Bailliere Tindall.

Saul, L.J. 1962. Psychosocial medicine and observation of animals. Psychosomatic medicine 24(1):58-61.

Searles, H.F. 1960. The nonhuman environment. New York: International Universities Press, Inc.

Smith, B. 1982. Unpublished paper on animal therapy with autistic children. Paper presented to the Society for Comparative Animal Studies, Paris.

Suomi, S.J., Harlow, H.F. and McKinney, W.T., Jr. 1972. Monkey psychiatrists. American Journal of Psychiatry 128(8, February):41-46. 